\title{
O DESENVOLVIMENTO DO COMITÊ PARA DEMOCRATIZAÇÃO DA INFORMÁTICA E A CIBERCULTURA: O CASO SERGIPE
}

\author{
THE DEVELOPMENT OF THE COMMITTEE FOR THE \\ DEMOCRATIZATION OF COMPUTERS AND CIBERCULTURE: THE \\ SERGIPE CASE
}

\section{EL DEVELOPMENT OF THE COMMITTEE FOR THE DEMOCRATIZACIÓN DE COMPUTERS Y CIBERCULTURE: EL SERGIPE CASE}

Resumo: Este artigo investiga a história do Comitê para Democratização da Informática em Sergipe. Trata-se de um estudo sobre uma Organização não governamental que objetivou promover a educação informal através das chamadas Escolas de Informática e Cidadania. A pesquisa abrange o período que vai de 1998, quando o CDI começou as atividades em Sergipe, até 2011, quando a ONG parou de funcionar no estado. O estudo foi norteado por procedimentos de história oral, no qual entrevistas foram realizadas com os atores envolvidos na construção do CDI Sergipe. Além disto, utilizamos documentos variados, tais como: registros contábeis, monografias, jornais, atas, o projeto pedagógico, manuais e material didático elaborados pela própria ONG. Todo este material foi considerado "documento/monumento" e, assim como indica Jacques Le Goff, foram questionados, desconstruídos e pensados como elementos para a produção de uma reflexão sobre a trajetória do CDI. Ao estudar a ONG e suas EICs, a pesquisa espera ter contribuido para a incipiente historiografia da educação digital em Sergipe.

Palavras-chave: Comitê para Democratização da Informática (CDI). Inclusão Digital. Organizações Não Governamentais.

Abstract: This article investigates the history of the Committee for Democratization of Information Technology in Sergipe. It is a study about a non-governmental organization that aimed to promote informal education through the so-called Information and Citizenship

Submetido em: 18/02/2018 - Aceito em: 15/03/2018 - Publicado em: 16/03/2018.

${ }^{1}$ Doutora em Educação pela Universidade Federal de Sergipe. Membro do Grupo de Estudos do Tempo Presente - GET/UFS. 


\section{Revista Docência e Cibercultura}

Schools. The survey covers the period from 1998, when the CDI began activities in Sergipe, until 2011, when the NGO stopped working in the state. The study was guided by oral history procedures, in which interviews were carried out with the actors involved in the construction of the CDI Sergipe. In addition, we use various documents such as: accounting records, monographs, newspapers, minutes, the pedagogical project, manuals and didactic material prepared by the NGO itself. All this material was considered "document / monument" and, as Jacques Le Goff points out, were questioned, deconstructed and thought as elements to produce a reflection on the CDI trajectory. In studying the NGO and its EICs, the research hopes to have contributed to the incipient historiography of digital education in Sergipe.

Keywords: Committee for Democratization of Informatics (CDI). Digital inclusion. Non Governmental Organizations.

Resumen: Este artículo investiga la historia del Comité para la Democratización de la Informática en Sergipe. Se trata de un estudio sobre una Organización no gubernamental que objetivó promover la educación informal a través de las llamadas Escuelas de Informática y Ciudadanía. La encuesta abarca el período que va de 1998, cuando el CDI comenzó las actividades en Sergipe, hasta 2011, cuando la ONG dejó de funcionar en el estado. El estudio fue guiado por procedimientos de historia oral, en el cual entrevistas fueron realizadas con los actores involucrados en la construcción del CDI Sergipe. Además, utilizamos documentos variados, tales como: registros contables, monografías, periódicos, actas, el proyecto pedagógico, manuales y material didáctico elaborados por la propia ONG. Todo este material fue considerado "documento / monumento" y, como indica Jacques Le Goff, fueron cuestionados, desconstruidos y pensados como elementos para la producción de una reflexión sobre la trayectoria del CDI. Al estudiar la ONG y sus EIC, la encuesta espera haber contribuido a la incipiente historiografía de la educación digital en Sergipe.

Palabras clave: Comité para la Democratización de la Informática (CDI). Inclusión digital. Organizaciones no gubernamentales.

\section{INTRODUÇÃO}

O comportamento da sociedade gerou novas práticas e novas representações. Chartier (1990) nos ajuda a compreender as noções de práticas e representações culturais, como interpretação sobre os processos vividos pelos homens e como esses registros constituem a nossa história como um conjunto de saberes adquiridos. As representações culturais possibilitam o desenvolvimento de novas concepções de processos que foram determinantes na formação da cibercultura, pela construção dos tempos históricos e suas modificações. Diante disso, pensamos em estabelecer um diálogo da cibercultura com as atividades e propósitos do CDI - Comitê para Democratização da Informática, uma ONG de inclusão digital que possuiu atividades em quase todo o Brasil e até fora do país. Neste contexto, a representação: 
permite articular três modalidades da relação com o mundo social: em primeiro lugar, o trabalho de classificação e de delimitação que produz as configurações intelectuais múltiplas, através das quais a realidade é contraditoriamente construída pelos diferentes grupos; seguidamente, as práticas que visam fazer conhecer uma identidade social, exibir uma maneira própria de estar no mundo, significar simbolicamente um estatuto e uma posição; por fim, as formas institucionalizadas e objetivadas graças às quais uns "representantes" (instâncias coletivas ou pessoas singulares) marcam de forma visível e perpetuada a existência do grupo, classe ou comunidade (CHARTIER, 1990, p. 123).

Podemos absorver as práticas, quer sejam múltiplas, diferenciadas e/ou conflitantes, como construtoras do mundo como representação. Logo, as relações sociais entre essas práticas e representações e o modo de ver das pessoas possibilitam entender a sociedade em uma determinada época, de acordo com o que essa sociedade representou naquele dado momento. Assim foi o berço que abrigou o CDI, num período que em Sergipe aconteceu de 1998 a 2011 e significou a formalização da abertura e fechamento das suas atividades.

Apesar das funções daquela ONG serem de um tempo em que o computador ainda não era uma ferramenta pedagógica democratizada, a inteligência coletiva2 produzida no CDI, como um dos principais motores da cibercultura, promoveu uma relação entre comunidade e tecnologia, que passou a definir a mudança social e de inclusão idealizada na missão e atuação do CDI. O aluno não precisava sair da sua localidade para ser inserido e para buscar sua qualificação profissional. O CDI nasceu na comunidade, para a comunidade e era, ao menos oficialmente, pela comunidade que deveria se manter e se retroalimentar.

As escolas do CDI funcionavam dentro de um conceito de escola não formal3 utilizando o computador para promover cidadania em comunidades carentes. Incorporando também o conceito de cidadania à prática pedagógica, Jorge Carvalho do Nascimento (2008) abordou o escotismo como uma escola de cidadania, lugar favorável a uma autoeducação. Em seu livro “A Escola de Baden-Powell”, enfatizou que a proposta daquela instituição era "tomar as ideias

\footnotetext{
${ }^{2}$ O conceito da inteligência coletiva foi criado a partir de alguns debates realizados por Pierre Lévy (1993), relacionados às tecnologias da inteligência como uma forma de pensamento originário pelas conexões sociais, possíveis pela utilização das redes na internet.

${ }^{3}$ A princípio podemos demarcar seus campos de desenvolvimento: a educação formal é aquela desenvolvida nas escolas, com conteúdos previamente demarcados; a informal como aquela que os indivíduos aprendem durante seu processo de socialização na família, bairro, clube, amigos etc., carregada de valores e culturas próprias, de pertencimento e sentimentos herdados: e a educação não-formal é aquela que se aprende "no mundo da vida", via os processos de compartilhamento de experiências, principalmente em espaços e ações coletivos cotidianas (GOHN, 2006, p. 28).
} 


\section{Revista Docência e Cibercultura}

dos meninos em consideração e incentivá-los a moldar sua própria vida”. O desenvolvimento social parecia ser o resultado almejado e cabia às instituições educativas o protagonismo em ações efetivas para a promoção das transformações prometidas. Esse preceito, ao que parece, podia também ser observado nas escolas do CDI, tendo em vista funcionar dentro da perspectiva de escola não formal.

Dessa forma, percebemos um importante vetor de ação do CDI, que foi o papel desempenhado pelas EICs - Escolas de Informática e Cidadania. Em Sergipe, a proposta funcionou durante quase treze anos, ajudando muitos jovens a serem inseridos no mercado de trabalho via inclusão digital. A técnica tinha o propósito de ser adquirida como um processo atitudinal, a fim de promover as mudanças que eram propagadas no campo individual e coletivo.

Podemos compreender o espaço das EICs como aquele que acompanha trajetórias de vida dos grupos ou indivíduos, fora desse ambiente formal (constituído por escola, professor, sala de aula, conteúdos sistematizados, enfim).

Deste modo, as EICs, esses espaços coletivos, participativos, de transmissão de saberes que puderam ser compartilhados, possibilitaram criar relações de pertencimento. Por isso a importância da proposta educativa contextualizada, ou seja, de saírem do seio da comunidade as possíveis soluções para os problemas enfrentados por ela. Eis o processo educativo que fundamenta as aulas nas EICs do CDI, cuja concepção de mundo deveria contribuir para um sentimento de identidade dentro da comunidade. Não era apenas questão de oferta ao "mercado de trabalho", mas também a valorização de uma semelhança coletiva que resultava no exercício da cidadania.

A história da educação digital em Sergipe, mais precisamente em Aracaju, foi iniciada na década de oitenta do século passado, quando houve uma necessidade de se utilizar o computador como ferramenta pedagógica. Era época das "escolinhas" de informática, do sistema S (Senac, Sesc, Senai, Sesi, Sebrae, Senar, Sescoop e Sest) oferecerem cursos de informática e, alguns anos depois, de as universidades formarem pessoal para trabalharem diretamente com a tecnologia4.

${ }^{4} \mathrm{O}$ chamado Sistema S cumpre um papel fundamental na oferta de cursos profissionalizantes em todo o Brasil.
Criado a partir dos anos 1940, as entidades que compõem o sistema se dedicam à formação profissional em suas
respectivas áreas de atuação (indústria, comércio, agropecuária, entre outras).
Fonte: http://www.brasil.gov.br/economia-e-emprego/2011/10/sistema-s-oferece-cursos-tecnicos-em-todo-obrasil. Acesso em: 02 jan. 2016. 


\section{Revista Docência e Cibercultura}

Nossa abordagem partiu da necessidade de historicizar uma época em que o computador foi objeto de luxo, restrito às camadas mais abastadas da sociedade. Um momento em que pessoas se uniram em prol de um objetivo: promover a inclusão digital de comunidades carentes. Esse movimento esteve presente em várias partes do Brasil (e fora dele), assim como em Sergipe e outros estados, as iniciativas promoveram várias ações de combate ao analfabetismo digital.

A metodologia de pesquisa reuniu diferentes recursos e procurou explorar várias possibilidades no decorrer da investigação. As principais fontes impressas utilizadas foram as seguintes: relatórios da equipe do CDI/SE, atas, fotografias, registros das ações do CDI na imprensa local e o projeto pedagógico do comitê. Mas também exploramos fontes orais. Cada um destes recursos foi tratado considerando as suas especificidades.

As entrevistas realizadas, norteadas pela história oral, ajudaram a compor o conjunto de fontes que foi complementando este trabalho, que já possuía outros documentos e imagens como registros integrantes do CDI Sergipe e do CDI Nacional/Matriz5. O estudo teve como recorte cronológico o ano de 1998, quando o CDI começou as atividades em Sergipe, até 2011, quando a ONG parou de funcionar no estado, fator que pontuou também uma análise acerca das razões que levaram ao seu fechamento (NUNES, 2017).

Desse modo, ao trazer do passado algumas memórias sobre o estabelecimento e atuação do CDI Sergipe, buscamos nos apropriar de acontecimentos históricos que marcaram esta instituição. A necessidade de se apossar da memória como objeto da História, parte da importância que a história oral vem adquirindo no campo da pesquisa, a qual nos acomodamos.

Uma abordagem ampla, a interpretação da história e das sociedades e culturas em processo de transformação, por intermédio da escuta às pessoas e do registro às histórias de suas vidas. A habilidade fundamental na História Oral é aprender a escutar. Gostaria de enfatizar que considero a História Oral como um campo interdisciplinar. (THOMPSON, 2006, p.20).

\footnotetext{
${ }^{5} \mathrm{O}$ perfil dos entrevistados está no final do presente trabalho, nas Referências. A intenção era ouvir todos os idealizadores, ou pelo menos a maioria deles, e assim, três foram entrevistados. Os membros do Conselho Diretivo e Funcionários também foram escolhidos na busca por uma maior representatividade. A pesquisa foi realizada com as seguintes pessoas: BARBOSA. Telma Oliva; BRAZIL, Osiris Ashton Vital; DIAS FILHO, Paulo do Eirado; GOMES, Márcia de Oliveira Alves; IAMAMOTO, Quimico; MELO. Vinícius Barbosa de; MENDONÇA. Daniele Andrade. MIRANDA, José Teófilo de; OLIVEIRAa, Jorge Santana de; OLIVEIRAb, Magnacilda. PRADO, Rosana Rezende Silva; ROCHA, Camila. RODRIGUES, Gladson; SANTOSa, Josenito Oliveira. SANTOSb, Roberto da Costa; SILVA, José Carlos da.
} 


\section{Revista Docência e Cibercultura}

Seguindo essa metodologia, Thompson propõe a utilização das entrevistas para enfatizar as histórias de vida dos sujeitos, no caso presente, da experiência das pessoas vinculadas de alguma forma ao CDI, salientando que a História Oral, através da mistura entre elementos objetivos e subjetivos, interessa-se por "compreender como as experiências do passado são reinterpretadas na memória" (2006, p.32).

Outrossim, como fundamentação teórica, trilhamos o caminho que trata da cibercultura, como uma estrada construída na relação de computadores que dialogam e que criam fenômenos sociais em que a internet é o canal, o mote, o início, o fim e o meio.

\section{PENSAR O CDI, PENSAR A CIBERCULTURA}

O objetivo é abordar a cibercultura como uma forma de relacionamento da sociedade com a informática, com as redes, com a multimídia, com os jogos eletrônicos, enfim, com os modos de navegação que produzem a comunicação dando-lhe sustentação. Essa cultura high $t e c h^{6}$ é proveniente da utilização do ciberespaço constituído pelas redes tipo internet e pelos computadores que se comunicam. Nessa circunstância, vinculamos o papel do CDI como aquele que, ao desenvolver sua cibercultura, a reutiliza em constante dinamicidade.

Assim, uma sociedade emergente, caracterizada como da informação ou do conhecimento, conectada por fios ou por wifi, formou uma base para que novas capacidades e novas organizações produzissem a sociedade ciber, cuja técnica e cultura se relacionaram, traduzindo os efeitos da tecnologia na sociedade (NUNES, 2017).

E neste novo desenho de sociedade, o ciclo de vida tecnológica se reinventa. Desde os primeiros aparelhos de videocassete às novas formas de assistir a um filme, aparelhos menores e com melhores resoluções, telas planas, lousa digital, reconhecedores de voz, olhares e impressões digitais, tudo isso já é passado. O futuro já se retroalimentou dele, e apenas esperamos os "próximos capítulos".

Para definir ciberespaço, Pierre Lévy (1999, p. 17) o enuncia como um novo meio de comunicação que surge da interconexão mundial de computadores, em que o referido termo representa não apenas a infraestrutura material da comunicação digital, mas também o universo oceânico de informações que ela abriga. Os seres humanos navegam e alimentam esse universo,

${ }^{6}$ High Tech ou high tecnology: alta tecnologia; tecnologicamente avançado. Ver: Dicionário de Informática, multimídia e realidade virtual (COLLIN, 2001, p. 200). 


\section{Revista Docência e Cibercultura}

determinando um espaço de diálogo aberto pela comunicação de mais de um computador.

Quanto à definição de cibercultura, o mesmo autor a define como o conjunto de técnicas (materiais e intelectuais), de práticas, de atitudes, de modos de pensamento e de valores que se desenvolvem juntamente com o crescimento do ciberespaço.

O ciberespaço criou a cibercultura, ou seja, o território da internet fundou uma nova (nem tão nova assim) forma de as pessoas viverem e se relacionarem. Nesse espaço, as redes de comunicação foram decisivas para a instalação de uma vida social e cultural, capaz de definir a sociedade em que estamos inseridos, promovendo não só mudanças nos hábitos, mas também na economia de regiões e países inteiros.

Toda comunicação desenvolvida pelo uso da tecnologia tornou a linguagem mais ágil, a escrita menos formal e as relações mais dicotômicas. Esses caminhos trazem o real e o virtual como uma questão importante quando utilizamos passado, presente e futuro para justificar ações ou modos de agir.

\section{O CDI SERGIPE}

O pioneirismo das práticas de inclusão do CDI foi algo que desde o início esteve em evidência. A população que estava no limiar da exclusão digital, não tinha acesso à tecnologia e a informação proveniente dela. O CDI Sergipe oferecia cursos de informática, reforço escolar e oficinas com as mais diferentes temáticas para comunidades carentes com o intuito de gerar inclusão e formar transformadores sociais.

O CDI Sergipe começou a fazer parte da Rede CDI em 1998. Ele foi criado por integrantes da Associação das Empresas Brasileiras de Tecnologia da Informação, Software e Internet (ASSESPRO/SE), por iniciativa do empresário José Teófilo de Miranda, que viu uma reportagem sobre a atuação do CDI no Rio de Janeiro, sede da entidade, e resolveu trazer aquela proposta para Sergipe. Assim, Miranda trouxe material didático e informações sobre como Sergipe poderia participar daquela rede que parecia crescer cada vez mais:

Eu era presidente da ASSESPRO, eu tinha as coisas ligadas à empresa, mas tinha o lado social, aí conversando com o pessoal que era da diretoria comigo, eu disse que a gente precisava fazer alguma coisa, informática pra comunidade carente... como? Sei lá, nunca dei aula pra nada, só a não ser para filho. Ficou aquela discussão. A gente com a vontade e sem saber por onde começar. Fui participar de uma reunião da ASSESPRO nacional na qual o Rodrigo Baggio era o diretor [idealizador e fundador do CDI no Rio de 


\section{Revista Docência e Cibercultura}

Janeiro, numa favela no morro Santa Martha, em 1995]. E todos já comentavam do nome dele, como aquele cara que tinha um projeto lá no Rio para comunidades carentes. Nem lembro se tinha internet na época. Depois fui ao Rio conhecer... mas tudo nasceu dentro da ASSESPRO, com os empresários do ramo da informática que queriam fazer alguma coisa, que queriam ter também uma atuação social (MIRANDA, 2015).

A base do CDI Sergipe funcionava no Centro de Incubadoras de Empresas de Sergipe (CISE), dentro da ASSESPRO, na capital Aracaju. O preâmbulo aconteceu dentro desta instituição, e um dos seus componentes, Osires Ashton Vital Brazil, foi convidado por Miranda para ser o responsável e ir até o Rio de Janeiro receber treinamento dado pelo CDI Matriz, a fim de que se tornasse um multiplicador na região. Brazil fez a capacitação da Vale, constituindo-se parte da primeira turma de capacitados para dar aula na Vale do Rio Doce, um dos principais patrocinadores do CDI:

Quando vim de lá [do Rio de Janeiro], já vim com um kit para reproduzir aqui. Veio todos os materiais. Começamos a procurar aqui as EICs. Tinha uma demanda de uma escola lá em Rosário do Catete, de uma escola muito complicada, que tinha muitos problemas e a gente começou então Rosário do Catete, Alessandro Alcino [Terra Dura], Cumbe, tinha a Joana de Angeles [Orlando Dantas], tinha nessa favelinha que fica aqui no pé da ponte que vai pra Barra que eu não sei o nome, tinha no Marcos Freire [...] Esse pessoal era capacitado por mim, às vezes no lugar e, às vezes, aqui na faculdade [Faculdade São Luís] que foi a capacitação que Josenito foi capacitado, ele fez aqui na sala de informática [Laboratório] dois ou três dias. Ele queria abrir uma escola na Paróquia do Orlando Dantas. Nessa época, o CDI ficava no CISE, a gente ficou lá até o CISE colocar a gente pra fora. A gente estava lá sem falar para ninguém. Depois o escritório foi lá para a Rua Laranjeiras, em frente aos Correios [em Aracaju/SE] (BRAZIL, 2015).

O trabalho solidário era uma bandeira nas ações de pessoas que possuíam atividades profissionais na área da informática, mesmo naquele tempo, com o computador ainda sendo inserido no cotidiano das pessoas. Esse grupo já pensava em fazer parte de um projeto coletivo e puseram o computador no centro das atenções, crendo que chegaria o dia em que analfabetos digitais significariam mais desemprego e piores condições de vida e de trabalho.

Ao abrirem um espaço para o relacionamento com pessoas que residiam em regiões pobres, os voluntários promoviam lentamente uma cultura digital em suas localidades. A informática passou pelo status de não significar apenas uma máquina que deveria ser manuseada, mas também a esperança de dias melhores, de um futuro que poderia estender as potencialidades humanas. 


\section{Revista Docência e Cibercultura}

Havia uma união de esforços que, em um primeiro momento, só foi possível pela proximidade das pessoas que formavam uma associação, e que contou com o apoio do então reitor da Universidade Federal de Sergipe, Prof. Dr. José Fernandes de Lima (gestão 1996-2000 e 2000-2004), no seu primeiro mandato, tendo em vista que o CDI funcionava na sede da incubadora da própria UFS.

A primeira EIC foi inaugurada no bairro que à época era chamado Terra Dura, oficiamente batizado de Santa Maria, na zona sul da cidade, tido como uma das comunidades mais carentes de Aracaju, principalmente por possuir ou abrigar o lixão da cidade. Para que a escola pudesse funcionar, eram necessários os computadores, evidentemente. Assim, foi realizada uma campanha que visava à doação de equipamentos usados e até mesmo quebrados, que eram recuperados por alguns dos membros da ASSESPRO/SE, que tinham empresas na área de informática, com venda, manutenção ou consultoria na área:

Conheci o CDI quando estudava administração em 2001, através de Ashton, que também estudava administração nessa época. Ashton era o facilitador na EIC que funcionava na Terra Dura [Alessandro Alcino] e me convidou para participar da escola lá, pois eu já atuava naquela instituição como voluntário. Era tipo um orfanato de meninos e eu morei lá um tempo. Então eu comecei a ajudar nas aulas, pois era aluno (SILVA, 2015).

O entrevistado acima, José Carlos Silva, tem uma história de superação. Foi um dos alunos do CDI, era menino de rua, morou no orfanato Alessandro Alcino, sediado no bairro na Terra Dura. Apesar de na entrevista não ter dado muita ênfase a essa época da sua vida, compreende que o tempo que passou na EIC foi importante, pois muitos ficavam ociosos e poderiam se envolver com outras coisas ruins, a exemplo das drogas. Entretanto, ele optou por assistir as aulas do CDI como forma de buscar um conhecimento que poderia ser importante para ele:

No início, as escolas ainda estavam em fase de idealização. Só em dezembro de 2000, foi que surgiu a primeira Escola de Informática e Cidadania - EIC do Estado, instalada no bairro Terra Dura [região periférica da cidade, que abrigava o depósito de lixo de Aracaju]. A montagem das EICs só foi levada a cabo através da realização de uma campanha para doação de computadores usados ou quebrados. Porém, até hoje elas enfrentam dificuldades, já que todas devem ser autossustentáveis. Isso significa uma dependência do trabalho voluntário, de pessoas capacitadas ao ensino da informática e da cidadania (SANTOSa, 2015). 


\section{Revista Docência e Cibercultura}

As EICs estavam localizadas, em sua maioria, em instituições instaladas em comunidades de baixa renda ou em seu entorno. Normalmente eram espaços cedidos, sem custo para a escola. $\mathrm{O}$ educador precisava deixar claro que a inclusão digital para acontecer deveria ir além das "aulas de informática" ministradas. O foco deveria ser a ampliação da escola para outras possibilidades, como atividades culturais e artísticas. A geração de trabalho e renda era um compromisso para a mobilização comunitária tomar corpo e ser absorvida pela população.

Havia uma supervisão que, além de capacitar o educador, dava apoio às EICs e subsidiava a avaliação da PPP - Proposta de Política Pedagógica, que era fundamentada na pedagogia freiriana, com um posicionamento claro a favor da liberdade, da justiça e da autonomia do ser humano, bem como da escola e da sociedade. A democracia, sob essa ótica, não acontece de uma hora para outra, mas sim, com liberdade e autonomia, fazendo parte de um processo construído. Assim, um conceito muito caro é o de democracia, enfatizado por Freire:

A democracia que, antes de ser forma política, é forma de vida, se caracteriza, sobretudo por forte dose de transitividade de consciência no comportamento do homem. Transitividade que não nasce e nem se desenvolve a não ser dentro de certas condições em que o homem seja lançado ao debate, ao exame de seus problemas e dos problemas comuns. Em que o homem participe (FREIRE, 1989, p. 80).

Ou seja, a proposta do CDI deveria fazer sentido com a forma de vida das pessoas, da experiência conjunta e da discussão dos problemas da comunidade. Essa comunicação que existia entre as pessoas dentro do CDI promovia a educação apregoada por Freire.

Assim, a perspectiva adotada por ele tinha tudo a ver com o modelo de uma educação como prática de liberdade, uma prática democrática, dialógica e reflexiva sobre os problemas existentes na sociedade. Essa educação, portanto, deveria vir das comunidades de bases, realizada por uma educação dita popular, promovendo transformação social, propondo políticas educacionais para que uma cultura própria gerasse uma escola voltada à problematização daquela coletividade.

Os educadores do CDI tinham que estruturar suas aulas por esse viés, norteando-se pelo que acontecia nas comunidades e como elas poderiam se organizar para resolverem problemas existentes. Logo, deveriam ser qualificados para essa missão, cuja proposta era multiplicar esse conhecimento para que brotassem instrutores da própria localidade.

Por essa razão, reuniam-se sistematicamente para traçar todos os detalhes sobre organização de eventos, de aulas, estimulando fóruns e debates. A EIC preparava a logística e 


\section{Revista Docência e Cibercultura}

divulgação dos cursos, como panfletagens, faixas, rádios comunitárias, informativos, distribuição de fichas de inscrições, certificados e compra do material do curso.

Para promover um crescimento ordenado, as aulas precisavam seguir uma metodologia própria, tanto em nível estratégico, quanto no pedagógico. Os capacitadores deveriam qualificar o educador que estaria à frente do CDI, mais precisamente voltado às EICs. Isso demandou tempo, planejamento e a busca por pessoas certas para a missão (NUNES, 2017).

Dentre as instituições parceiras, as paróquias, em várias oportunidades, abriam as suas portas entendendo que se tratava de um projeto social que beneficiava a comunidade em que estava sendo instalado. Isso não era feito de forma aleatória. Para essas instituições religiosas ou comunitárias, o valor agregado em possuir uma EIC em suas dependências não era algo para se jogar fora. Eram ações que entravam na conta e poderiam ampliar o número de fiéis também.

Para que uma EIC funcionasse, o CDI oferecia a metodologia de implantação e o desenvolvimento de seu PPP - Projeto Político Pedagógio, com a criação e execução de um plano de capacitação e acompanhamento para o coordenador e educadores dessas escolas. $\mathrm{O}$ coordenador participava de muitas capacitações, para que pudesse ser um agente multiplicador na sua região, junto às escolas do seu estado, garantindo ainda um plano de sustentabilidade para o desenvolvimento da EIC.

Os projetos eram planos que deveriam ser muito bem executados, para que refletissem no sucesso das investidas do CDI no estado em que estivesse atuando. Era necessário disseminar a dinâmica do curso, iniciar com as expectativas dos participantes e a explicação da PPP, que partia do princípio de que os educandos eram sujeitos ativos do processo de ensinoaprendizagem, partícipes das aulas com suas experiências de vida, algo importante para o desenvolvimento de projetos de trabalho com temas concretos que remetessem às questões de Cidadania e da realidade do meio.

Os temas discutidos nas aulas eram problematizadores. Direitos, deveres e obrigações apareciam nos textos trabalhados pelos educadores (para aprender a utilizar o processador de textos Word, por exemplo). Eram assuntos que, em geral, permeavam as relações cotidianas, no trabalho, na família e as atitudes que poderiam ter em relação ao bem comum. Os alunos eram provocados a buscarem soluções para os problemas exemplificados naqueles textos.

Muitas vezes as discussões sobre as aulas partiam de algum fato polêmico ocorrido à época e que tivesse chamado atenção do grupo. Esse fato deveria surgir, preferencialmente, a 


\section{Revista Docência e Cibercultura}

partir dos educandos, ou então por meio de notícias de jornais e revistas, textos ou músicas que tratassem diretamente do tema, para possibilitar uma maior reflexão sobre eles ${ }^{7}$.

As experiências de vida formavam identidades coletivas capazes de agrupar soluções produzidas por esses próprios sujeitos. Stuart Hall (2006) situou o indivíduo em processos de grupos e nas normas coletivas, as quais subjaziam a qualquer contrato entre sujeitos individuais. $\mathrm{Na}$ visão do autor citado, os sujeitos são formados através de sua participação em relações sociais mais amplas e pelos papéis que esses indivíduos desempenham, como um modelo sociológico interativo.

Dentro dessa conclamada coletividade, os projetos desenvolvidos no CDI eram estruturas vivas, que nutriam a relação de parceria dos atores envolvidos (equipe da EIC, CDI e comunidade), a fim de que existisse uma corresponsabilidade na gestão e na busca de resultados eficazes de transformação social:

Não é possível à sociedade revolucionária atribuir à tecnologia as mesmas finalidades que lhe eram atribuídas pela sociedade anterior. Consequentemente, nelas varia, igualmente, a formação dos homens. Neste sentido, a formação técnico-científica não é antagônica à formação humanista dos homens, desde que ciência e tecnologia, na sociedade revolucionária, devem estar a serviço de sua libertação permanente, de sua humanização (FREIRE, 1996a, p. 156-157).

A tecnologia como divisa para uma autonomia coadunava com a proposta de Freire (1996a), na discussão sobre as burocracias que percorriam a revolução que ele conclamava. Não é nosso objetivo entrar no debate por ele desenvolvido sobre opressores e oprimidos, nem no sentido que estabelece sobre a prática da liberdade e Marx como práxis educacional. O que extraímos de Freire diz respeito ao sentido do contexto do educando, em se problematizar as questões culturais e econômicas partindo do local de onde aquele educando fala, e, preferencialmente, de onde o educador também esteja inserido. Logo, nos interessou entender a apropriação que o CDI fez da sua pedagogia.

\footnotetext{
${ }^{7}$ A preocupação com uma certa padronização nas aulas era constante. Rodrigo Baggio, fundador do CDI, manteve contato e buscou uma parceria para confecção de materiais mais pedagógicos, como uma espécie de manual, para que não houvesse uma desconfiguração no estilo das aulas. Este material foi elaborado pelo Núcleo de Informática Aplicada à Educação (NIED), da Universidade Estadual de Campinas UNICAMP, sob a coordenação geral do Prof. Dr. José Armando Valente, então Coordenador do Núcleo de Informática Aplicada à Educação (NIED - UNICAMP), que juntamente com uma equipe, preparou alguns cursos inserindo a base da proposta do CDI pelos preceitos de Paulo Freire. Eram cursos de Informática, de Word, Excel, PowerPoint, Projeto Geração de Renda aproveitando lixo para reciclagem, cursos para elaborar jornal comunitário, programação, manutenção de computadores, dentre outros.
} 


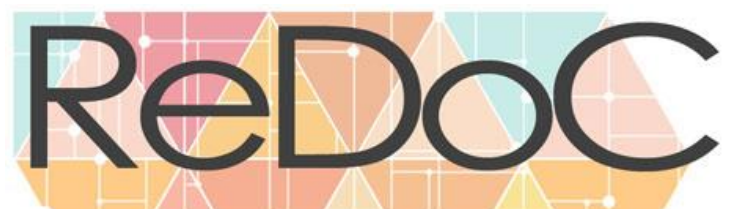

Revista Docência e Cibercultura

A troca de experiências entre as EICs fazia com que o projeto ganhasse uma identidade cada vez mais definida, pelo menos o objetivo inicial foi o de constituir uma franquia social, e para isso tornou-se necessário um certo padrão nas ações desenvolvidas pelas escolas.

Outro ponto importante era a questão estrutural de vida útil dos computadores. Normalmente eram bastante usados e manuseados por pessoas inexperientes, o que muitas vezes fazia com que quebrassem ou se desconfigurassem com muita facilidade. Em muitos casos, era uma fonte ou uma placa que deixava de funcionar, e, assim, um técnico para resolver esse tipo de problema era alguém imprescindível a fim de impedir que o projeto não parasse e a escola continuasse a funcionar.

A organização financeira do CDI estava baseada e sustentada em projetos e parcerias que se instalaram na medida em que as ações do CDI também ganharam mais visibilidade. Um dos primeiros simpatizantes foi o Dom José Palmeira Lessa (1942- ), arcebispo de Aracaju, que cedeu um andar inteiro de uma galeria que a Arquidiocese possuía na frente da sede dos Correios, no centro da cidade. Era uma sala grande que começou a funcionar como base do CDI. Nas palavras de Miranda:

A ideia da gente inicialmente era procurar CNPJ para fazer escolas. Então nós fomos atrás de quem já fazia caridade, como as igrejas católicas, os centros espíritas, comunidades de bairro... A gente procurava um lugar que recebesse a responsabilidade de receber os cinco computadores que eram liberados. Tinha a Matinha, do lado de empacotamento de cocaína, embaixo da ponte que hoje vai dar na Barra dos Coqueiros. Daí a ideia foi essa e a gente foi colocando as EIC nas comunidades. Tinha muita gente comprometida, o Erik do Marcos Freire, a Romana, atrás da igreja, a dona Conceição da Barra, que se dedicavam demais (MIRANDA, 2015).

O CDI Sergipe atuou ativamente para aumentar os resultados e as estatísticas da regional: mais de cem computadores alocados e mais de cento e oitenta educadores capacitados. A participação era em grande parte com trabalhos voluntários nas EICs ou na sede do CDI Sergipe, além das campanhas de doação de equipamentos novos ou usados. Ainda havia investimentos para financiar a ONG com treinamentos, muitas vezes com participação das empresas chamadas de parceiras em projetos especiais, planejados e executados junto com a equipe do CDI.

Os problemas em relação à sobrevivência do CDI começaram a aparecer por volta do ano de 2010. Com toda uma estrutura de empresa, o CDI Sergipe começava a receber certa pressão do Parque Tecnológico que o abrigava. Como não pagava pelo espaço utilizado, outras 


\section{Revista Docência e Cibercultura}

empresas de base tecnológica pleiteavam a vaga do local onde funcionavam o escritório e uma sala de capacitação dentro do Parque Tecnológico de Sergipe.

Além disso, não bastavam apenas a vontade de voluntários nem campanhas para doação de computadores. O CDI Sergipe precisava de recursos financeiros. Havia folha de pagamento, energia, impostos, telefone e uma sistematização de operações para dar suporte às EICs em funcionamento.

Em Sergipe, o voluntariado tinha limitações. O Conselho Administrativo (diretoria) tentava promover divulgação das ações do CDI, porém, todos tinham atividades laborais, não podiam ter dedicação exclusiva à causa da inclusão digital. Daí a importância de um mínimo de pessoas trabalhando como equipe, sendo funcionários e resolvendo os problemas do cotidiano.

\section{CONSIDERAÇÕES IMPORTANTES}

O CDI ocupou dois momentos em Sergipe. O primeiro teve à frente o grupo de idealizadores que trouxe o projeto e era formado por integrantes da ASSESPRO/SE. Nesse agrupamento havia uma identidade, uma missão e compromisso com a causa da inclusão. Cada um desses integrantes contribuía com aquilo que sabia fazer.

O segundo momento demandou mais profissionalização. Havia conselho fiscal, equipe do marketing e da publicidade, da gestão e da estatística. Eram contextos diferentes e visões diferentes para um mesmo objeto, ou será que ainda era o mesmo objeto? Hobsbawm nos ajuda a compreender a importância desse olhar ao dizer que "é muito importante que os historiadores se lembrem de sua responsabilidade, que é, acima de tudo, a de se isentar das paixões de identidade política — mesmo se também as sentirmos" (HOBSBAWM, 1997, p. 22).

Por essa razão, os depoimentos dos entrevistados foram importantes para demarcar essas fases. As variadas perspectivas sobre o ciclo de vida do CDI em Sergipe possibilitaram uma análise mais crítica da realização de uma proposta que foi idealizada e até mesmo romantizada. As pessoas discorrem sobre suas experiências com sentimentos que carregam as paixões e suas emoções.

Já mencionamos que existia por parte do CDI Matriz (Rio de Janeiro) uma sugestão de que as parcerias partissem dela própria. Isso era o que ocorria com a Vale, que distribuía recursos para vários CDIs regionais, sempre a partir do CDI Matriz. Segundo a coordenadora 


\section{Revista Docência e Cibercultura}

de projetos, Magnacilda Oliveira (uma das entrevistadas), durante muito tempo a matriz não permitiu parcerias que não fossem articuladas através dela, o que, de certa forma, engessou as regionais. No momento em que o produto do CDI foi ficando obsoleto, os gerenciadores da Matriz transferiram para os setores regionais a responsabilidade de se manterem. A partir daí, contraditoriamente a Matriz deixou de inserir nas suas parcerias as unidades regionais. Havia uma preocupação grande da unidade central em manter os salários de sua própria equipe e não mais o das equipes da rede. Isso fragilizou alguns estados que foram perdendo seu fluxo de atividades.

Ainda em relação ao fechamento do CDI/SE, outro fato relevante em algumas entrevistas foi o caso das EICs possuírem máquinas já defasadas, pelas doações de equipamentos, muitas vezes, quase sem condição de uso. As grandes empresas e fundações passaram a possuir seus próprios centros tecnológicos, com máquinas modernas. $\mathrm{O}$ investimento para manter o CDI/SE funcionando era alto, partindo do princípio que era necessária uma equipe mínima de quatro profissionais: um técnico de informática, uma pedagoga, uma assistente social e a gestora de projetos: perfil do quadro que compunha a última equipe do CDI/SE.

Entendemos que o próprio modelo praticado pelo CDI foi se desgastando pela inserção das TICs no cotidiano das pessoas e no seu processo educacional. Diante disso, compactuamos com a afirmação de Castells (2003), de que a sociedade transforma a tecnologia, principalmente em se tratando de tecnologia da comunicação. Assim, a vida das pessoas é profundamente afetada, tal qual as comunidades onde o CDI atuava.

Se os processos de mudança social partem do movimento social como aquele de ação coletiva de segmentos da sociedade para defesa de certos objetivos ou interesses - podemos supor que a premissa "ação local, visão global" deixou de ser verdadeira na medida em que uma certa ruptura potencializou o deslocamento do CDI Sergipe do CDI Matriz.

Convém reafirmar que, como proposta de inclusão digital que buscou promover a cidadania, o CDI foi precursor em Sergipe. Não existia um formato que buscasse unir técnica à noção de cidadania, ou seja, à condição do indivíduo em viver em comunidade politicamente e socialmente articulada, de forma a interligar direitos e deveres, com vistas a uma sociedade mais justa. Essa organização funcionou como rede, em uma época em que o conceito de rede era diferente. As redes interligavam as EICs aos CDIs de cada região e estes, ao CDI Matriz. 


\section{Revista Docência e Cibercultura}

A nosso ver, o sistema entrou em colapso na medida em que políticas públicas, até então inexistentes, passaram a se estabelecer como supridoras das lacunas que antes eram campo de atuação de ONGs, as quais nasciam para atender determinadas demandas da sociedade. Dentre essas atuações públicas, lembremos do Projeto Um Computador por Aluno (UCA) que foi implantado com o objetivo de intensificar as tecnologias da informação e da comunicação (TIC) nas escolas, por meio da distribuição de computadores portáteis aos alunos da rede pública de ensino. Ou seja, as políticas públicas estavam sendo aplicadas na resolução de problemas que nasceram na ausência delas.

Estimular uma comunidade a exercer a cidadania partia da instrumentalização dessa consciência pelos direitos e obrigações de modo a garantir sua aplicabilidade. E, nesse sentido, as EICs tinham essa disposição, constitucional em sua essência, posto que o exercício da cidadania deve ser um dos maiores objetivos da educação de qualquer país.

O CDI se tornou uma franquia social, tendo sido pioneiro nisso em quase todos os estados do Brasil, inclusive fora do país, levando essa marca como um portal de possibilidades. A promoção da cidadania era uma bandeira e seus alunos deveriam ser agentes de transformação nas suas comunidades, atuando de maneira ativa e responsável. Nesse aspecto, pensamos que essa tarefa foi executada com êxito, ao observarmos os depoimentos colhidos, tendo o cuidado de considerar o tempo e o espaço daquelas ações.

As EICs formaram embriões que foram gestados no ciberespaço. Nesse comparativo, como organismos em constante desenvolvimento, talvez o modelo autônomo e autossustentável estivesse ainda precisando o útero materno. Ao deslocar a EIC do CDI, a instrumentalização que ficou mais evidente foi a proposta da inclusão social, considerada a alma do CDI e necessária para continuar o ciclo de vida, independente da celula mater.

Sem querer produzir uma espécie de "escola privada para pobre" - termo utilizado em algumas reuniões internas -, o afastamento entre o CDI Sergipe e a Matriz provocou justamente essa situação, mesmo as escolas ainda exibindo na parede o quadro com a missão de promover a inclusão social por meio da tecnologia.

Todavia, se a cibercultura nasceu da relação entre comunidade e tecnologia, sim, o CDI foi (ou é) um exemplo de um fenômeno social coligado às comunicações e ao ciberespaço. Essa correlação sociocultural deriva do nexo entre a sociedade, a cultura e as tecnologias. Nesse contexto, as comunidades que receberam a proposta do CDI ampliaram e popularizaram a 
utilização da Internet e outras tecnologias de comunicação, possibilitando assim maior aproximação entre as pessoas.

Convém, entretanto, ressaltar que o fato de popularizar o uso da internet não significa dizer que foi franqueada a sua democratização. O ciberespaço não é democrático. A liberdade é um conceito cada vez mais limitado nesse lugar, que não está sujeito somente à vontade dos seus consumidores, posto que é regrado a leis e a condicionamentos. Basta abrir um email em algum provedor dito gratuito para perceber o rol de produtos e serviços que são "aleatoriamente" colocados à disposição do usuário.

Outro fato pertinente é também considerar que, para a expansão do CDI, o contexto político e econômico foi muito importante. A ausência de políticas públicas para resolver o problema da exclusão digital e a conjuntura neoliberal, em que se buscam alternativas capazes de favorecer o desenvolvimento econômico do nosso país.

A proposta da inclusão digital/social disseminada pelo CDI, paradoxalmente, propunha uma economia autossustentável, mas na medida em que os recursos acabaram, pelo menos no caso do CDI Sergipe, o sonho também acabou.

Os esforços dos integrantes da última composição do CDI/SE poderiam ter sido semelhantes ao empenho que o grupo inicial dos idealizadores tiveram, mas a formação de um comitê alheio à comunidade, como foi o caso do CDI Sergipe, impulsionou uma decrescente motivação numa dedicação com mais afinco às atividades da organização. Pessoas cada vez mais ocupadas com suas funções laborais tributavam a outras pessoas uma disponibilidade que não tinham por falta de tempo. Tudo isso aliado a projetos que acabaram tendo uma atenção maior por parte do CDI Matriz a outras regionais com maior visibilidade perante os patrocinadores e mantenedores, também foram minguando recursos que inviabilizaram a manutenção da regional Sergipe.

Outrossim, a iniciativa realizada em Sergipe foi considerada pioneira no modelo de inclusão digital no estado, levando em consideração a proposta de promoção da cidadania. $\mathrm{O}$ fato de já existir um formato muito mais de informática educativa em alguma escola pública sergipana, como aventado no depoimento de Oliveira(a) (2016) não descarta o protagonismo do CDI como proposta de educação digital. O objetivo da escola pública era muito mais de utilizar o computador como uma ferramenta pedagógica, do que promover uma autonomia do sujeito conscientizando-o a ser agente do seu próprio exercício da cidadania. 


\section{Revista Docência e Cibercultura}

Sob a ótica dos idealizadores, o modelo era desenvolvido para incluir o excluído, a fim de que esse pudesse ser o ator principal da sua vida, buscando conhecimento, educação e empregabilidade. O sujeito deveria exercer sua cidadania como uma marca indelével, inexorável e definitiva que pudesse traduzir aquele espaço público de promoção do bem-estar social.

Ao finalizar as atividades em Sergipe, não apenas os membros da diretoria concordaram que não haveria mais como manter uma estrutura que demandava custos fixos como aluguel, luz, telefone, folha de pagamento e impostos. No entanto, o próprio CDI Matriz não colaborou para que outras possibilidades pudessem ser admitidas para a manutenção do escritório em Sergipe.

Uma sociedade emergente, caracterizada como da informação ou do conhecimento, conectada e desenvolvida por uma cibercultura, deve ser dinâmica na medida em que forma uma base para que novas capacidades e novas organizações produzam uma também nova sociedade cuja técnica e cultura se relacionam.

Mesmo diante de todas essas nuances, é bem verdade também que o CDI continuou (e continua) presente em alguns outros lugares, mesmo diante das adversidades e problemáticas, algumas das quais já destacadas aqui.

De uma certa forma, o CDI precisou se reinventar. Prova disso está na sua forma atual de se apresentar, definindo-se como uma "organização social voltada ao empoderamento digital, que busca formar jovens autônomos, conscientes e conectados, aptos a reprogramar o sistema em que estão inseridos, por meio do uso da tecnologia"». Inclusive as campanhas publicitárias anunciaram uma nova "marca", abandonando o agora antigo nome CDI para abraçar o novo denominado RECODE ${ }^{9}$.

O site foi todo reconfigurado e intensificada a parceria com instituições comunitárias, bibliotecas e escolas públicas "para formar multiplicadores, que replicam nossos programas para o público final. Juntos, formamos uma grande rede de educadores, professores e bibliotecários para promover uma nova consciência e gerar oportunidades aos jovens brasileiros. Estamos presentes em sete países e nove estados brasileiros e impactamos até hoje mais de 1,68 milhão de vidas". O site ficou mais interativo, com opções para as pessoas se

\footnotetext{
${ }^{8}$ Informações extraídas do "novo" site do CDI, reconfigurado para <www.recode.org.br> Acesso em: 20 out. 2016.

${ }^{9}$ Ao que parece, a mudança de nome do CDI para RECODE foi fruto de um processo judicial referente a direito de marcas e patentes que teria como autora uma instituição denominada CDI existente no Paraná.
} 


\section{Revista Docência e Cibercultura}

cadastrarem para atuar como educadores ou parceiros. Também é possivel verificar que existe um ícone do lado direito da tela principal, para pessoas que desejam atuar na região metropolitana de São Paulo ou Rio de Janeiro possam realizar seus cadastros para educadores. Simples assim.

Democratizar a informática deixou de ser o problema. O chamado "empoderamento digital" reprogramou um sistema e procura agora redefinir uma nova cibercultura, criada por uma nova plataforma e novo recomeço.

Para finalizar, é interessante pontuar como a construção da história é um elemento da narrativa. O filme americano "Amnésia”, lançado em 2000, nos mostra um homem que sofre de um tipo de amnésia que impossibilita que lembre de fatos que acabaram de acontecer. Leonard Shelby, o protagonista, precisa fazer registros que sabe que irá esquecer. Porém, são informações que ele vai montando para arrumar sua memória ou criar sua história ou sua verdade em eventos que constróem o mundo como representação.

Se, por um lado, os esquecimentos produzem uma história, a memória prodigiosa também as produz, mesmo que em sentido inverso. Jorge Luis Borges, escritor e poeta argentino, no seu conto Funes, o Memorioso, narra a história de um rapaz cuja memória o transformava numa enciclopédia viva, mas que não conseguia articular tantas informações para elaborar conhecimentos (BORGES, 1975).

No contexto do CDI, o que isso significa? Que tanto os apagamentos quanto as lembranças definidores da nossa memória possibilitaram apenas escrever uma parte da história do CDI, vivida por pessoas que ora tiveram sua amnesia, tal qual o protagonista do filme, ora foram exímios "Funes", como o personagem de Borges.

Nesse sentido, as outras histórias que começam a ser contadas, neste momento sob uma lente chamada "recode.org.br", metaforicamente nos propicia esquecer o que vimos ou ouvimos e até mesmo o que vivemos. E assim, uma nova página começa a ser escrita com as mais variadas cores, fontes e (res)significações de histórias que parecem não possuir fronteiras nem verdades absolutas.

Atualmente, o próprio site do CDI não está mais no ar, ou seja, vários caminhos de pesquisa, inclusive aqui mesmo citados, não possuem mais destino certo. Isso reforça a importância em se produzir pesquisas como essa, para concretizar uma história que por não ter sido ainda contada e/ou por conter fragmentos na virtualização, pode, simplesmente, ser apagada ou desconstruída entre cliques e atualizações. 


\section{Revista Docência e Cibercultura}

\section{REFERÊNCIAS}

BORGES, Diva. Pelos Excluídos no Mundo Digital. In: Revista Gestão Empresarial, ano 3, $\mathrm{n}^{\circ} \quad 9, \quad$ p. 10-13, jul./ago./set./2008. Disponível em: <http://issuu.com/gestao25/docs/gestao9> Acesso em: 19 nov. 2015.

BORGES, Jorge Luis. Funes, o memorioso. In: Ficções. São Paulo: Círculo do Livro, 1975, p. 109-118.

BOURDIEU, Pierre. O poder simbólico. Trad. de Fernando Tomas. Lisboa: Difel, 1989.

. A economia das trocas simbólicas. Introdução, organização e seleção Sergio Miceli. São Paulo: Perspectiva, 2007.

CASTELLS, Manuel. A sociedade em rede. Tradução Roneide Venâncio Majer. São Paulo: Paz e Terra, 1999.

. A galáxia da internet: reflexões sobre a internet, os negócios e a sociedade. Tradução Maria Luiza X. de A. Borges. Rio de Janeiro: Zahar, 2003.

CDI. Cidadania Digital: como o CDI utiliza a informática e a e a educação para promover a inclusão social e transformar vidas. Rio de Janeiro: Ediouro, 2005.

COLLIN, S.M.H. Dicionário de informática, multimídia e realidade virtual. Tradução Antônio Carlos dos Santos e Regina Borges de Araújo. São Paulo: Companhia Melhoramentos, 2001.

FREIRE, Paulo. Educação como prática da liberdade.19. ed. Rio de Janeiro: Paz e Terra, 1989.

Pedagogia do oprimido. 23. reimpr. São Paulo: Editora Paz e Terra, 1996a.

Pedagogia da autonomia: saberes necessários à prática educativa. 35. ed. São Paulo:

Editora Paz e Terra, 1996b.

Educação e atualidade brasileira. São Paulo: Cortez, 2001.

GONH, Maria da Glória. Teoria dos Movimentos Sociais: Paradigmas Clássicos e Contemporâneos. São Paulo: Edições Loyola, 2002.

Educação não-formal, participação da sociedade civil e estruturas colegiadas nas escolas. Ensaio: aval. pol. públ. Educ., Rio de Janeiro, v.14, n.50, p 27-38, jan./mar. 2006. Disponível em: <http://www.scielo.br/pdf/ensaio/v14n50/30405.pdf> Acesso em 10 jun. 2016.

HALL, Stuart. A identidade cultural na pós-modernidade. Tradução Tomaz Tadeu da Silva, Guaracira Lopes Louro. 11. ed. Rio de Janeiro: DP\&A, 2006.

HOBSBAWM, Eric J. A Era das Revoluções. Rio de Janeiro: Paz e Terra, 1977.

. Sobre História. São Paulo: Companhia das Letras, 1997.

LE GOFF, Jacques. Memória. In: LE GOFF, Jacques História e Memória. 5 ed. Campinas: Editora da UNICAMP, 2003. p. 419-476.

LÉVY, Pierre. As tecnologias da inteligência: o futuro do pensamento na era da informática. Tradução Carlos Irineu da Costa. Rio de Janeiro: Ed. 34, 1993.

O que é o virtual? Tradução Paulo Neves. 1.ed. São Paulo: Ed. 34, 1996.

Cibercultura. Tradução Carlos Irineu da Costa. 1.ed. São Paulo: Ed. 34, 1999.

NASCIMENTO, Jorge Carvalho do. A escola de Baden-Powell: cultura escoteira, associação voluntária e escotismo de Estado no Brasil. Rio de Janeiro: Imago, 2008.

NEGROPONTE, Nicholas. A vida digital. Tradução Sérgio Tellaroli. São Paulo: Companhia das Letras, 1995. 


\section{Revista Docência e Cibercultura}

NUNES, Cristiane Tavares Fonseca de Moraes. BITS de Inclusão em Sergipe: uma história da educação digital no Comitê para Democratização da Informática. Tese (Doutorado em Educação) - Universidade Federal de Sergipe, Sergipe, 2017.

PELlANDA, Nize Maria Campos; SCHLÜNZEN, Elisa Tomoe Moriya; SCHLÜNZEN, Klaus (Orgs.). Inclusão Digital: tecendo redes afetivas/cognitivas. Rio de Janeiro: DP\&A, 2005.

PESAVENTO, Sandra Jatahy. História \& História Cultural. Belo Horizonte: Autêntica, 2005.

\section{ENTREVISTAS}

BARBOSA. Telma Oliva. Entrevista concedida à pesquisadora. Aracaju, 28 de setembro de 2015. A entrevistada é Administradora e atualmente é responsável pela área de Desenvolvimento Humano e Organizacional do BANESE - Banco do Estado de Sergipe, contato: (79) 3218-1549/email: telma@ banese.com.br.

BRAZIL, Osiris Ashton Vital. Entrevista concedida à pesquisadora. Aracaju, 05 de agosto de 2015. O entrevistado é administrador e professor da FSLF. Foi fundador do CDI Sergipe. Contato: (79) 99977-2423. Email: ashton.brazil@gmail.com.

GOMES, Márcia de Oliveira Alves. Entrevista concedida à pesquisadora em 03 de agosto de 2016. A entrevistada é facilitadora do CDI Comunidade Obra Social Nossa Senhora do Rosário no Município de Rosário do Catete/SE. Contato: (79) 99917-9137. Email: mg.bonita@hotmail.com

MELO. Vinícius Barbosa de. Entrevista concedida à pesquisadora. Aracaju, 29 de setembro de 2015. O entrevistado é bacharel em Ciência da Computação e funcionário do BANESE (porém atualmente está afastado, pois reside no Canadá). Contato +17789806677. Email: vbmelo.ca@ gmail.com.

MENDONÇA. Daniele Andrade. Entrevista concedida à pesquisadora. Aracaju, 28 de agosto de 2015. A entrevistada é administradora. Contato: (79) 99962-8573. Email: danieliak@hotmail.com.

MIRANDA, José Teófilo de. Entrevista concedida à pesquisadora. Aracaju, 02 de outubro de 2015. O entrevistado é geólogo e empresário. Foi presidente do SERGIPETEC e fundador do CDI Sergipe. Contato: (79) 98833-8818. Email: teofilo.demiranda@gmail.com.

OLIVEIRAa, Jorge Santana de. Entrevista concedida à pesquisadora. Aracaju, 28 de outubro de 2015. O entrevistado é Engenheiro Civil e Empresário. Já foi Secretário de Estado. Contato: (79) 99133-6644 ou 3211-5122. Email: jsantana@infox.com.br.

OLIVEIRAb, Magnacilda. Entrevista concedida à pesquisadora. Aracaju, 07 de setembro de 2015. A entrevistada é administradora e foi funcionária do CDI Sergipe. Contato: (79) 99991-1893. Email: magna_oliveira1117@hotmail.com.

PRADO, Rosana Rezende Silva. Entrevista concedida à pesquisadora. Aracaju, 21 de setembro de 2015. A entrevistada é assistente social e foi funcionária do CDI Sergipe. Contato: (79) 99978-8898. Email: rosanarezende@ oi.com.br.

ROCHA, Camila. Entrevista concedida à pesquisadora. Rio de Janeiro, 24 de outubro de 2016. A entrevistada é graduada em Administração de Empresas. Atualmente é Gerente de Relacionamento na ONG Recode. Contato: (21) 2558-5695. Email: camila.rocha@ recode.org.br 


\section{Revista Docência e Cibercultura}

RODRIGUES, Gladson. Entrevista concedida à pesquisadora. Aracaju, 22 de setembro de 2016. O entrevistado foi o responsável pela EIC do Município de Cumbe no interior de Sergipe, aluno e facilitador. Atualmente trabalha no Atacadão como representante de produtos. Contato: (79) 99693-5575. Email: gladsonrodrigues@ hotmail.com.

SANTOSa, Josenito Oliveira. Entrevista concedida à pesquisadora. Aracaju, 13 de setembro de 2015. O entrevistado é economista e professor da Universidade Tiradentes (UNIT). Foi facilitador e do conselho. Contato: (79) 9978-6910. Email: josenito@infonet.com.br.

SANTOSb, Roberto da Costa. Entrevista concedida à pesquisadora. Aracaju, 21 de agosto de 2015. O entrevistado é administrador e empresário. Foi fundador do CDI Sergipe. Contato: (79) 3246.4031 ou 99117-3787. Email: robertodacostasantos@ gmail.com.

SILVA, José Carlos da. Entrevista concedida à pesquisadora. Aracaju, 30 de setembro de 2015. O entrevistado é administrador e bacharel em Direito. Atualmente é Supervisor da Corregedoria da Guarda Municipal de Aracaju. Contato: (79) 98836-5678. Email: felixrevive@ig.com.br. 